\title{
The "Great Northern Wilderness" in the Works of the Educated Youth Writer Liang Xiaosheng*
}

\author{
Jinhuan Shi \\ Far East Institute \\ Heihe University \\ Heihe, China
}

\begin{abstract}
As the generative space of Educated Youth Writer Liang Xiaosheng's works, the Great Northern Wilderness not only demonstrates its own "regional" characteristics, but also presents readers with its humanistic significance. In the works of Liang Xiaosheng, although the Great Northern Wilderness seems like an "uncivilized region", it has accepted and nurtured survivors and developers from generation to generation with its great mind. Its "wildness" brought suffering to the educated youth come there, but also built up their persevering quality and healthy body. It was not only a land of suffering but also a land of spiritual and physical growth and a land of salvation for them.
\end{abstract}

Keywords-Great Northern Wilderness; regional characteristics; humanistic significance

\section{INTRODUCTION}

Since 1970s, the writer Liang Xiaosheng has been writing one and another unforgettable "stories of the educated youth" and most of the generation places of those stories are rooted in the "Great Northern Wilderness". In Liang Xiaosheng's view, the "Great Northern Wilderness" is like a combination of God and Devil. It nurtured a generation and generation of people in Great Northern Wilderness and cultivated their pure nature by virtue of its rich and natural god ship and also built up their quality especially for their firm and persistent quality by virtue of its magic power. For the educated youth, the Great Northern Wilderness is not only their land of suffering but also the place witnessed their growth.

\section{GREAT NORTHERN WILDERNESS: A WILD AND UNTAMED PLACE OF ORIGIN}

As a concentrated generative place of literary discourse, "Great Northern Wilderness" was commenced from the starting of the Liberation War. In late 1940s, more than 100 farms were built up in Heilongjiang region in the manner of developing the Great Northern Wilderness in response to the call of the state to support the Liberation War. Some writers began to write and artistically demonstrate the charm of the "Great Northern Wilderness" in succession to eulogize the contribution of the Great Northern Wilderness made to the

*This paper was funded by the Research on "Acceptance" of Liang Xiaosheng's Educated Youth Novel under the Philosophy and Social Science Fund Planning Project of Heilongjiang Province in 2014 (14E097). national liberation and economic construction. Poets such as Lu Qi, Zhong Shan, Guo Xiaochuan and Nie Wei as well as writers such as Zong Tao have praised the Great Northern Wilderness in their works in different aspects. Different from those carol typed description, Liang Xiaosheng's description about the Great Northern Wilderness more prominently illustrated the wild and untamed nature of the original place. Representation of natural scenes such as the frosty climate, the sky full of heavy snowstorm and the Ghostly Marsh eating people shows the reader another aspect of the Great Northern Wilderness and also renders the hard living conditions of the educated youth who developed the Great Northern Wilderness.

His novel "This is a Mysterious Land" displays the horror of the "Ghostly Marsh" by describing the hard course of the educated youth in developing the "fully covered wasteland". In the beginning of the novel, Liang Xiaosheng represents the natural conditions of the "Ghostly Marsh" in a gloomy tone: "It is a deathly great marsh covered with deadwood, withered leaves and poisonous alga. The dark brown stagnated water surface appears hypocritically calm. In the abyss of mud underwater, there are rotten bones of bears, guns of hunters and tractors of land reclamation team... It exudes the breath of death within a hundred miles. People call it the 'Ghostly Marsh' "[1]. Then he depicts a night of the ghostly marsh having forces of evil in the way of folklore. Wherein, the scenes of green and bling wildfire and the strange yelp of the soul-collecting birds and so on engraved by him makes reader horrified when reading it. Behind this horrible "Ghostly Marsh", there is a concealed vast expanse of fertile soil. This fertile soil becomes a temptation that attracts Li Xiaoyan, Wang Zhigang and other pioneers to "advance" toward it. When more than ten members of land reclamation team came to the fully covered wasteland with great enthusiasm and aspirations and attempted to conquer it, the plague, food shortage and siege of wolves and other bad conditions made them hurt seriously: "My" sister Shanshan was swallowed by the ghostly marsh; leader Li Xiaoyan died due to the plague and the "Moor" Wang Zhigang was eaten by wolf when battling with wolves in order to escort "me" and political instructor. Although $\mathrm{Li}$ Xiaoyan and other pioneers opened up the road to help the latecomers realize the dream of reclaiming the wilderness, the original wild untamed nature of Great Northern Wilderness still left a deep 
impression on the pioneers and its ferocious face got the educated youth pioneers' striving covered with a dark color.

In addition to the "Ghostly Marsh", the frosty snowstorm weather is another natural appearance of the Great Northern Wilderness. In his novel "A Storm is Coming Tonight", he combines the overwhelming trend of the educated youth's returning to city with the "snowstorm" of the Great Northern Wilderness to get the narration of the work to a climax. It not only highlights the delirious mind of the educated youth to return to city, but also illustrates the raving scene of the harsh winter of Great Northern Wilderness. The combination caused the tragedy of life of the protagonist Pei Xiaoyun.

When the educated youths held torches, waiting anxiously in the harsh winter night for the permission of returning to city, an overtaking of snowstorm appeared, reflecting the hardships of living environment in the Great Northern Wilderness and the complicated psychology of the educated youth. "Just like typhoon raising very heavy billows on the ocean, the violent snowstorm on the wilderness was thrilling. ... It's not a yowl but a sharp whistling, like a mad woman's cry. Under the bleak moonlight, the tidehead-like high snow wall moves fast toward and overwhelming them from the wasteland. The gale was like a pair of invisible giant hands, raising the thick snow from the wilderness rudely, smashing it into snow powder and scattering it into the air. It seems like thousands of brooms waving wildly between the heaven and earth...." [2]. This description about the snowstorm of Great Northern Wilderness is written from far to near views, getting readers firstly hear the sound and then see the shape and finally showing its extremely strong aggressiveness and destructive power. Under the influence of this climate, more than 800 educated youths began to get stuck in the spiritual confusion and behavioral violence. Their demonized performances such as smashing the canteen, fighting and abuse and so on shew readers the distortion of human nature in the extremely cold climate. However, it was right in the mad circumstances between the heaven and earth that the female educated youth Pei Xiaoyun having pure heart and nice dream was frozen to death on her post. A girl who was right in teenage age was frozen to death for reason of being forgotten. Compared with the cold of the Great Northern Wilderness, what seems more chilling might be the indifference concealed behind human nature. Here, the snowstorm of Great Northern Wilderness is not only represented in aspect of natural landscape but is even mixed with many humanistic connotation.

This description of the natural landscape of Great Northern Wilderness is also embodied in Liang Xiaosheng's other works such as "Annual Ring ", "Snow City", "Educated Youth" and "The Age of Return City". For example in the "Educated Youth", Liang Xiaosheng describes a story that Qi Yong, Zhao Tianliang and Xiaodibao encountered with snowstorm suddenly while erecting wires and almost lost their lives; while in "The Age of Return City", he also indirectly wrote the plot that the educated youth Yang Wenwen's hand was frozen off when she was watering on the skating rink. It can be said that the wild and untamed nature of the Great Northern Wilderness provides the atmosphere for Liang Xiaosheng's writing about the educated youth and renders the atmosphere for unfolding the fate of the educated youths.

\section{GREAT NORTHERN WILDERNESS: A LAND OF SUFFERING FOR THE SETTLERS}

Although the natural environment of the Great Northern Wilderness is very harsh, the large fertile soil on the land attracted a batch and batch of pioneers. In 1960s in response to the call of Chinese government, many educated youths dreaming to make something greatly different in the vast land came to the Great Northern Wilderness and determined to turn the Great Northern Wilderness into a great northern warehouse. Of course, the wild and untamed natures of the Great Northern Wilderness are not so easy to be conquered. In the narration of Liang Xiaosheng, the Northern Wilderness made the educated youth taste the utmost sad and pains, but the abundance and richness of the Great Northern Wilderness also nurtured the educated youth and built up their persevering spiritual qualities.

The Great Northern Wilderness brought one after another suffering for the reclamation work of the educated youth depending on its unique natural environment. The Ghostly Marsh and snowstorm were as daunting as demons. However in real life, what is more memorable for the educated youth was the paradox of continuous autumn rains against "harvesting". The description on link between autumn harvest and autumn rain is a necessary plot in Liang Xiaosheng's works about the Great Northern Wilderness. In his works, "rush harvesting of wheat" is usually used to describe the harvest on the Great Northern Wilderness. The reason why "rush" is used is because there is a terrible "rainy season" coming almost at the same time as the wheat harvest season. The "autumn rain" of the Great Northern Wilderness may make the pioneers gain nothing from their hard works in the year. Therefore in this place, the autumn harvest seems to be a "war". Their enemy is not other one, but the "autumn rain." The short story "For the Harvest" describes the suffering of sudden autumn rain brought to the pioneers. The continuous autumn rain seems like demon and behemoth "looking down the quiet wheat sea in a sinister and ferocious way". "In this lead-grey space between sky and earth, the golden wheat sea in the clear day became a corroded copperlike rust yellow sea. A piece and piece of wheat sea started being overwhelmed..." [2]Under the scouring of autumn rain, the originally fruitful wheat sea was faced with the fate of being rotted. His work "Educated Youth" also contains the scene of rush-harvesting of wheat in the rain. "The wheat harvesting team ranked in long rows, standing on the edge of the wheat sea. In the wheat sea, harvester towed by tractor is still working. The thick dark clouds overwhelmed the wheat sea. In the distance, there was a faint thunder. "[3] In order to rush harvest wheat, the educated youths either harvested or eagerly eaten Baozi and Manto in the cold autumn rain, with blisters raised and even bleeding on their hands. The pain is like what Zhao Tianliang said: "with respect to the rush harvesting of wheat in heavy rain, it was not a job that human beings could dealt with."'[3]

Although the continuous autumn rain became the nightmare of "harvesting persons" in the Great Northern 
Wilderness, what makes the pioneers more fear is the plague that accompanied with it the rain. "Hemorrhagic fever" is like a like Death, created an atmosphere of death on the North Wilderness that trembles under the autumn rain fall. As indicated in "This is a Mysterious Land", team leader $\mathrm{Li}$ Xiaoyan died from hemorrhagic fever when she was still young and beautiful; in "For the Harvest", the old commander was also died from hemorrhagic fever. "It takes away human life, just like blowing out a candle. It is so cold and ruthless, and even refuses to leave any time for man to fight against it. "[2] And in the Great Northern Wildness under extremely simple medical conditions, the sufferers could only depend on the five medical kits to save their lives.

However, it was right under the suffering of this "hard" life that pioneers of the Great Northern Wilderness finally conquered it, making the place becoming the great northern warehouse. In a manner of speaking, it was the suffering in the Great Northern Wilderness that created the pioneers there, especially for the strong mind of the educated youth. In the Great Northern Wilderness where the climate is harsh, the living conditions are extremely difficult and medical conditions are extremely backward, what the pioneers mainly depended on is their own hands, wisdom and strong vital force.

\section{A BiRTHPlace OF PURE NATURE}

What the educated youth relied on for living in the Great Northern Wilderness also contains the loving and faithful, warmhearted and friendly natures of people living in the place, in addition to the tough quality of themselves. As Yang Bingkui, who lived in the old Great North Wildeness as described in the "Educated Youth", said: "The Great Northern Wilderness is actually a very humane place." [3] This kind of human sentiment also infected the educated youth who came and "rooted" there, making them give up the originally selfish and narrow-minded nature of them, overcome hard conditions and become mature gradually by the solidarity and friendship among them.

The "Educated Youth" published in 2012 is a representative work that focuses on the pure nature of people living in the place. The old people of the Great Northern Wilderness Yang Bingkui, the early pioneer Commander Zhang, the secretary of Shandongtun village Liang Xixi and so on all like the elders, treating each educated youth in good faith. When Yang Bingkui saw the feeble and poor Shanghai educated youth Zhou Ping being refused due to her inferior family background, he resolutely arranged Zhou Ping in the reclamation group regardless of her background. When Commander Zhang who has the characters of soldier saw Zhou Ping's feet being worn to blister and unable to walk, he naturally carried her behind his back. In his opinion, the value of human life is far more than his capitalistic identity. Meanwhile Liang Xixi, as a female and secretary of Shandong Yi, shows mother-like loving care for the educated youth like Zhou Ping rather than discriminating and abusing Zhou Ping. In addition, Liang Xixi also braved the cold and led the villagers to rescue the educated youths such as Qi Yong, Zhao Tianliang and Xiaodibao who were almost frozen to death at midnight. Under the loving care of people living in the Great Northern Wilderness, the educated youths finally sustained through the hard times and gained physical and mental growth and maturity.

Moreover, the pure and kind-hearted nature nurtured by the Great Northern Wilderness also infected the educated youths, making them becoming mature from young, selfless from selfish and narrow-minded and making confession for their previous contemptible behaviors. The Moor and "I" in "This is a magical land" were originally caught in the vortex of fighting for acquiring the love of Li Xiaoyan. However, the land and suffering of the Great Northern Wilderness purified their souls. Finally, the Moor was eaten by wolf in order to protect the reclamation achievements and rescue the lives of his comrade. In the novel "Snow City", the political instructor Yao Yuhui was theeldest daughter of the mayor. But, the living in the fertile land of the Great Northern Wilderness built up her earthy soul and emotion-righteous quality. After returning to city, she was not accustomed to the identity of the mayor's daughter. She was unwilling to raise her impression by virtue of her parents' relationship, but borrow her parents' identity again and again to relieve her comrades. She was deeply disturbed and even felt guilty when she witnessed the predicament of her comrades after returning to city. The only thing that would make her feel warm and proud in the bustling urban life was always the times that they spent in the Great Northern Wilderness. Not only Yao Yuhui, but other educated youths also treated and helped each other as brothers and sisters after returning to city. This scene gives us an impression of the deep and honest nature of the fertile land. In the novel "Annual Ring", Liu Zhenqing, Xu Ke, Wang Xiaosong, Han Debao, Zhang Meng and Hao Mei jointly performed a touching story of friendship. Changes of the times are like molding clay figurines that their fate can be kneaded back and fro, letting them taste the doubled sad feeling in the world. While the only power that makes them break through the suffering is "friendship" that they never gave up. Among them, Zhang Meng was originally a selfish and proud "Miss". But for the purpose of earning the opportunity to return to city, she even abandoned her "true love" and betrayed her body. However, the tolerance and selflessness of the Great Northern Wilderness gave her the sublimation of humanity. Finally, she repented for her betrayal against Liu Zhenqing and was grieved for Hao Mei's misfortune. In the novel "Educated Youth", Wu Min was originally an "ultra-left" female. She persecuted the simple Zhou Ping because of her father's political background and even even burnt girls' dormitory and disclosed Shen Li's privacy so that Shen Li got "mental illness" under her persecution. Nevertheless finally, she was emotionalized by the life experience and friendly comrades in the Great Northern Wilderness so that she could go to participate in Shen Li's art exhibition after returning to city. Although she concealed her face and did not communicate with any comrade, her appearance undoubtedly represented her repenting for his "sin".

\section{CONCLUSION}

In novels of Liang Xiaosheng, the Great Northern Wilderness is not only a natural existence, but also an 
organism of human culture. It nurtured a generation and generation of people in the "Great Northern Wilderness" and nurtured a batch and batch of pioneers. It also transfuses pure nature into each life in addition to giving them healthy body.

\section{REFERENCES}

[1] Liang Xiaosheng. This is a mysterious land [M]. Xinhua Publishing House, 2010 (08): 163.

[2] Liang Xiaosheng. A storm is coming tonight [M]. Wenhui Press, 2009 (6): 72, 145, 153.

[3] Liang Xiaosheng. Educated Youth [M]. Qingdao Publishing House, 2012 (06): 51, 65, 8 